\title{
Bubbles \& Bridges: A Family's Experience of Disability
}

\author{
Sheri Klassen ${ }^{1}$ \\ ${ }^{1}$ Faculty of Rehabilitation Medicine, University of Alberta, Edmonton, Canada \\ Email: sheriannetteklassen@gmail.com
}

As we have worked hard to minimize the threat of a new virus on our families and friends, there has been a lot of talk about "bubbles." Stories of bubble-living during the pandemic, of its virtual boundaries, the protection it provides, and its tendency to create disconnection have all felt naggingly familiar. Recently, I recognized that bubbleliving is how my family has been navigating life for many years. Any venture beyond the boundaries of our intimate family life has always come with risk.

My children live with neurodevelopmental disabilities. From the birth of our first child, both protective instinct and necessity helped to build our family bubble. Its inception, much different than the conscious and deliberate creation of COVID bubbles, this bubble has been formed reflexively and reactively by forces within and without. From within, our overriding motivations are of love and efforts to understand; from without, motivations (even well-intentioned) can be undermined by ableist perspectives and inadequate social structures and supports. On both sides, our family has had to manage a myriad of expectations which endlessly collide with the realities of who our children are, with what my husband and I can offer as parents, and with what the world can offer. Bubble living softens the impact of these collisions.

We also build a lot of bridges. We start with managing expectations, then we adapt and find ways to meet our children closer to where they are. In writing this, I am leveraging what is a current and widespread appreciation of bubble living - demanded by a virus - to foster understanding of what it is like for those of us who have lived in bubbles long before COVID.

Life inside our bubble feels comfortable in part because of the protection it provides, but also because, admittedly, we do have a lot going for us. Our bubble happens to be in a country that has relative economic stability and is able to offer my children social and medical support, as well as access to decent public education. My husband and I have had the ability to successfully engage in existing structures of advanced education, which has resulted in steady work as physicians. I am aware that many others' bubbles sit more precariously than ours does. I also know that sometimes there is no real threat to leaving our bubble; that I am operating from a place of defensiveness. Given the repeated challenges that our family has had to navigate inside and outside our bubble, we have become bruised and sensitive to the risk.

My husband and I created our bubble because our children's differences frequently confound all manner of expectations: ours as parents, institutional expectations, those created by the conventions of organized activities, and even those that define casual interactions and friendships. Preconceived notions of family life have made it hard at times for my husband and I to see our children clearly. Expectations have needed to shift to accommodate real neurodevelopmental challenges. Many assumptions have ultimately been restructured. Within the safety of our bubble, where outside forces are filtered, these shifts can happen more easily and graciously. That said, our process of adaptation is often messy and fragile and has as much to do with us as parents as it does with disability. Some expectations my husband and I hold are particularly resistant, and are taking years to shift, such as those that narrowly define "good behavior" and "achievement." However, in our role as loving parents we are motivated to recalibrate expectations so they resonate better with who we are, who our children are, and to make room for acceptance and honor.

Our commitment to restructure expectations, develop unique connections, and see new, previously unappreciated strengths in our children, fortifies our bubble from within. We forge patterns of communication and even physical movement that are shaped by our quirks and capacity rather than by social conventions. For example, my son is better able to listen when he does not make eye contact. As a result, common requests to "look me in the eyes to show you are 
listening" have made my son feel everything from frustrated to unsafe. In our home, we no longer require that he look us in the eyes to show he is listening. When my daughter faces challenges, I have learned to circumvent conventions of "doing," "fixing," and even "talking about it." Sometimes it is only when such expectations are surrendered that she can move forward. For us, adaptations like these become the bridges inside our bubble.

Whenever we leave our bubble, we are quickly reminded that all the shifts and bridges we work so hard to build inside do not exist outside. Instinctively, I want to limit the exposure of our differences. While there are attempts at bridge-building outside our bubble, those involved are often caught unprepared, inadequately supported, and/or sometimes not equipped (emotionally, experientially, and/or strategically) to accommodate our family's specific differences. Interactions outside our bubble are therefore often mired in hesitation, tension, anxiety, and disappointment. Sometimes the process leaves me devastated. Other times, I am able to reflect on the years of work that were required to build our "inside" bridges and can be more gracious. I can offer tools and hard won perspective(s) to facilitate bridge-building "outside." Ultimately, however, staying within our bubble is the surest way to avoid being affronted by perspectives that presume inability rather than capacity, and to maintain both real and perceived safety.

School is one of the dominant institutions that exists outside of our bubble, one where both overt and unseen expectations abound. My children's experiences of school are very different from the confidence and ease I have always felt within the education system. Formal education provided a way for me to move beyond the constraints faced by my parents whose lives did not allow them to achieve high school diplomas. School is a place where my capacity and skills are consistently validated, a place I actively and repeatedly choose to go to seek new knowledge and challenges. For my children, however, school is often a place of struggle and uncertainty about how their neurological differences will be received. In his elementary years, it became clear that our son's differences were often positioned and/or viewed as deficit. One teacher erroneously assumed that my son could not write when, in fact, he was writing his own little books at home and neither we, nor his previous teachers, had been consulted about his capacity. In a later year, following this same pattern of presumed incompetence, one aide actually referred to him as a "zombie." It was no surprise when my son eventually expressed that he felt scared when receiving aide support.

I continue to highly value education and, as a parent involved in guiding my children through it, I have come to appreciate how complex it can be to teach diverse learners. Unfortunately, there have been many other instances where bridge-building was scarce, and I have been left reeling and disappointed in a system that I have trusted so deeply. Conversations with my son's Elementary administration about the tendency toward a deficit focus, inconsistent efforts at inclusion, and the sense my children were viewed as burdensome, were often met with complacency. I am grateful that we have had some well-supported school years and I know classrooms are challenging spaces, but I was confused when the administration resisted my efforts to provide government-funded therapists to offer additional support.

Outside of school, I marvel at the excitement of families when they register their children for summer camps or extracurricular activities, confident of the potential for participation and fun. They seem to carry little weight or worry beyond concerns about cost, scheduling, and availability. For our family, these activities require preparatory conversations with instructors to ensure accommodations can be made. Should our children be accepted, we are then compelled to share what we have learned from our bridge-building with both children and organizers. Sometimes, it also includes the frantic recruitment of an aide. Most parents do not seem to imagine their children could be rejected or sent home from a program for any reasons other than injury or ill-health. For us, even after all the effort and presumed accommodations, my children can still be rejected. Upon completing a lesson, a music teacher at a private studio once announced to a busy waiting room, that included my children, that they could not be taught music.

Established institutions and structured activities aside, I also suspect that beyond the navigation of naps, meals, and schedules, most families do not consider playground visits, playdates, or running into acquaintances as being much of an undertaking. But, I do. For me, all these seemingly benign events come with effort and risk. I wonder how my children will be perceived. I wonder if based on how they move or act, others will feel uncomfortable and then might come a variety of awkward glances. In those moments, the ability to build bridges feels beyond reach. Sometimes defensive, sometimes for good reason, I worry that not only at school but in the day-to-day, so much of who my children are - their uniqueness, humanity, and wholeness - will be perceived as deficit.

Long-standing bubble-living feels unfair. It feels unfair that "outside" is a place where our differences can be viewed as unwelcome or inconvenient. Created and sustained by exclusion and uncertainty, our bubble has become a source of protection, but also a source of increased isolation. I have even felt wary and vulnerable when someone from "outside" 
seems to burst in and engage with our differences freely and with kindness. At first, it feels like a breach of our defenses and is a little threatening, and then it feels like a desperate longing has been quenched. Alternately, I have experienced an outsider's hesitancy to engage or sit in our bubble because our differences become uncomfortable.

Sometimes, especially after a rare birthday party (one of the most risky of bubble departures) or a rare play date that stretched my energetic and creative ability to keep it going, I want to retreat and stay put in our bubble. As tempting as that is, I know it is not good for me or for my kids to only live inside our bubble. Aside from detrimental effects on personal mental and physical well-being, it does nothing to weave diversity into my community, which is something I really want. So, we take tentative steps outside again and again. We have successes. We take hits. I am in awe when my children, for whom the outside world is often bewildering and painful, are still willing to take the risk.

Everyone needs a place to let their guards down, and my family will continue to rest in the comfort of all the supportive bridges we have built within our bubble. I also want to find more strength and stamina to build more and better bridges outside our bubble. I have seen how tensions are eased when there is a practice of flexibly shifting expectations on both sides. When advocacy is engaged thoughtfully, opportunities for connection and success are nurtured. When others are able to meet us part way, gaps can be bridged together. I also want my children to learn selfadvocacy, experience agency, all while comfortably showing their difference. I want to create opportunities to quench that sense of longing and for all the amazing things my children have to offer to be received. I want their community to help them learn the beauty and power of reciprocity. I know that this can only be achieved when my children leave our bubble.

I am thankful for scientists around the globe who have helped us navigate COVID bubbles. My other bubble, the one that has been adapted and reinforced over the years - the one that has taught me that I do not need eye contact to know someone is listening and that sometimes the best thing to do is nothing - has real value and will likely never fully go away. But, as some of us continue the project of moving in and out of our more permanent bubbles, I feel I can draw on the wisdom of our public health specialists. At this time when COVID bubbles still remain in some places, they keep telling us that awareness and staying informed is key. They ask us to be kind and gracious, to be open and ready to shift expectations. They remind us that even within our bubbles, each of us can do our part; that we are all in this together. 